\title{
Reading nano: the public interest in nanotechnology as reflected in purchase patterns of books
}

\author{
Joachim Schummer
}

Owing to a rapidly growing public interest in nanotechnology, people are increasingly buying various books to inform themselves about nanotechnology. This paper tries to measure the public interest in nanotechnology and its relation to the public interest in other fields of knowledge by applying a new method. I combine formal network analysis of co-purchase book data with traditional content analysis. The method is successful in identifying the books that the public reads to be informed about nanotechnology, and in distinguishing between different kinds and classes of books and thereby between different interest foci and readerships and their relations. The results suggest that nanotechnology is for many their first intense contact with science and technology and that they read a great variety of different kinds of books. Rather than choose general introductions to current research written by scientists or science journalists, readers focus on forecasting and visionary literature including business guides, written by software entrepreneurs and business consultants. Unlike expert readers, who connect nanotechnology to other fields of science and engineering, the broader public connects it to visions about dissolving the human/machine distinction. Although the distinction between non-fiction and science fiction is still important for readers, border-crossing authors increasingly blur it.

\section{Introduction}

Nanotechnology is currently attracting researchers from many different disciplines. Whether they change or just re-label their research, scientists increasingly use the term "nano" to describe their activity, at a tremendous speed such that, if the growth rate of the past five years continues for only two more decades, almost all research will be called "nano" (Schummer, 2004a). There is no doubt that in the fields called "nano" numerous scientific and technological breakthroughs have been made and that cutting-edge research is being done. Yet, it is difficult to specify what they have in common other than meeting standard definitions of nanoscience and nanotechnology, which are notoriously vague. Such definitions usually require only that research objects have some new properties to be investigated and exploited which are determined by their 1-100 nanometer size or structure. ${ }^{1}$ Since these 
definitions apply to most of chemistry, condensed matter physics, materials science, molecular biology, and so on, there is plenty of room for nanoscale research, indeed. ${ }^{2}$

However, the tremendous rise in interest has different origins. On the one hand, many countries now spend huge amounts of money for nanoscale research. This is frequently considered a competition between the United States, Japan, and Europe, in which nobody wants to lag behind. In the United States, a broad coalition of national departments and agencies, from the National Institute of Health to the Department of Defense, joined forces with the US President in 1999 to found the National Nanotechnology Initiative in order to coordinate, foster, and fund research. Since 2000 the budget has almost quadrupled from $\$ 270$ million to $\$ 961$ in 2004, and funds have been secured by an extra Nanotechnology Bill for the next four years. On the other hand, nanotechnology, since its first visionary outline by Eric Drexler in 1986, is expected to radically change our world. The US National Science and Technology Council still appears modest when claiming: "The effect of nanotechnology on the health, wealth, and lives of people could be at least as significant as the combined influences of microelectronics, medical imaging, computer-aided engineering, and manmade polymers developed in this century" (NSTC, 2000: 13). Other visions, which we meet later, go even as far as to promise immortality and indefinite wealth. At the same time, critical visionaries begin to warn that, if the power of nanotechnology will be so great, there is also great danger of abusing that power to the detriment of humanity and the environment.

The re-orientation of much of current research, the unusual governmental efforts, and the debates between positive and negative utopians of nanotechnology have induced a strong public interest. People want to know what nanotechnology is about, why their government spends so much money on research into it, and how it may change their life. Whether this is a renaissance of the public interest in science or just a temporary phenomenon, it is a unique opportunity to study what particular aspects of science people are interested in, what kind of information they look for and actually receive, and how this is going to shape the public view of science and technology.

Most scholarly approaches in the public understanding of science focus on the relationship between science and the public, whether they subscribe to the "deficit model" or favor one of the other forms of interaction between science and the public, such as citizen participation, dialogue, science shops, consensus conferences, and so on. ${ }^{3}$ Since all these models require some kind of mediation and/or mediator to establish and cultivate the relationship between science and the public, the public understanding and view of science essentially depends on the kind of mediation. It appears that this is particularly important for nanotechnology, so that the first scholarly studies in the public understanding of nanotechnology all focus on media presentations. ${ }^{4}$ For instance, Lewenstein and Radin (2004) have shown that during the rapid growth of the newspaper coverage of nanotechnology in recent years, a firmly positive image has been prevailing, i.e. that journalists have mediated a positive image of nanotechnology.

Like these media studies, the present paper focuses on mediation. However, in contrast to newspaper and magazine articles, which people receive with their newspapers and magazines, whether they are interested in nanotechnology or not, books have been chosen as the medium of study, since people selectively buy books to inform themselves about nanotechnology. That allows investigation of the public interest in nanotechnology within the scope of available books. Since books are usually more complex than newspaper articles, I go beyond the positive/negative image dichotomy and analyze what specific views on nanotechnology are mediated through the books and locate the public interest in nanotechnology within the general reading interests. Looking at both the demand for information 
(the public interest in nanotechnology) and the supply of information (the kinds of available books on nanotechnology) provides a dynamic perspective on the public understanding and view of science.

The first task then is to identify the books that people read to inform themselves about nanotechnology (Section 3.1). This requires a new research method that draws on purchase data of online bookstores and formal network analysis (Section 2). On the basis of document analysis and a classification of these books and their authors, I analyze in Section 3.2 what kinds of books people mainly read, and what books are frequently read together. Finally, I investigate how nanotechnology, in the view of the public, is related to other fields of literature, both non-fiction (Section 4.1) and fiction (Section 4.2). The overall results not only provide precise ideas of the structure of the public interest in nanotechnology and the supply of information, but also suggest what perspectives will dominate future public debates on nanotechnology.

\section{Methodology}

There are two ways to identify the books that the public reads to be informed about nanotechnology. Approach 1 starts with some criteria of what a book on nanotechnology is, identifies the available books according to these criteria, and finally establishes a ranking according to some numbers about reading customs. Because nanotechnology is a very vaguely defined and fuzzy field, approach 1 is difficult to pursue and runs the risk of ending up with a very incomplete list. Approach 2 starts with any exemplary book A on nanotechnology and investigates what other books B, C, D, etc., people read along with book A. By following the same kind of links from each of the books B, C, D, etc., and then again from the resulting books, and so on, approach 2 draws a network. In this network, books are the nodes that are linked to each other by the relation of co-reading. As the network expands with further research, structure appears because not every book is linked to each other. One such structural feature is a cluster, defined by a set of books which are strongly linked to each other but only poorly to other books, and which stands out in network visualizations as a particularly dense area of interconnected nodes. In approach 2 , such a cluster, if there is any, identifies a fuzzy set of books that the public reads to be informed about nanotechnology. Since the realm of nanotechnology is supposed to be fuzzy, approach 2 is more appropriate here.

There are further reasons why the network approach is the method of choice in our case. First, because many different kinds of books on nanotechnology have been published, the analysis of the network cluster promises to provide insight into the relationships between these kinds of books, particularly between technical and non-technical books. Second, researching the network beyond the fuzzy cluster boundary provides information on how nanotechnology books are connected with the reader's interest in other books, including both fiction and non-fiction. Third, data on co-reading, or to be more precise on co-purchasing, of books are easily available on websites of major online bookstores, who have the feature of "Customers-who-bought-this-book-also-bought-those-books." Since Amazon.com lists up to 20 other book titles here, compared to others such as Barnes \& Noble who list only six titles, this website is the best place for extensive data collection. It should be mentioned that, since all the customers must register once at online bookstores, their co-purchase pattern covers not only one deal but also all the purchases during the entire period of registration, such that they may easily provide a very specific reading profile for each customer. 
The network approach allows application of formal network analysis for which a welldeveloped mathematical theory has been available for several decades. ${ }^{5}$ The theory, which is nowadays implemented in standard software for network analysis and visualization, is broadly used for studying social and organizational structures and for citation analysis in bibliometrics. ${ }^{6}$ For a given set of network data, consisting of nodes and connections that are mathematically represented by a topological matrix, mathematical analyses can provide a formal characterization of the network and its elements. For instance, centrality analysis orders the nodes according to their numbers of links to other nodes; cohesion analysis yields clusters of nodes that are strongly connected to each other and only loosely connected to other nodes; equivalence analysis identifies nodes that are structurally similar, for example, by bridging two clusters or by being similarly connected within a cluster, connectivity analyses provide the path between any two nodes or the relative degree of connectivity of the network and its subnetworks.

The network of books that the public reads to be informed about nanotechnology was identified by Amazon.com data from mid-March 2004, including sales ranks (see Table 1 below). The books were ordered, not from an online bookstore but from a library, and read and analyzed according to several criteria, including the type of book (for classification criteria see Section 3.2), the intended readership, the readability for general readers, etc., which have been used for further analysis. In addition, information about the authors was collected either from the books or via Internet research. For data analysis and visualization, the software NetMiner II by Cyram Co. Ltd was used. ${ }^{7}$

Although librarians appreciate the information from major online bookstores even for their reference purposes, ${ }^{8}$ it has not yet been used for research in the public understanding of science. I owe the idea of using Amazon.com's co-purchase data for network analysis to a New York Times article (Eakin, 2004) on fascinating research about the customs of reading political books by Valdis Krebs, who is a specialist in network analysis and software. Krebs could show, both in 2003 and 2004, that there is a strong barrier of political information flow, such that liberal readers read only liberal books and conservative readers read only conservative books (Krebs, 2003, 2004). As early as 1999, Krebs applied the method to describe rather isolated "communities of interest" around certain theories in terms of copurchase patterns and to identify "bridging books" that connect these communities with each other by shared interest (Krebs, 1999).

Since the network analysis of co-purchase patterns is a new method for analyzing the public understanding of science, and thus subject to broad criticism, I discuss some possible objections to point out its limitations and advantages as well as possible future improvements. I start with more general objections and finish with quite specific and technical ones.

1. Because the network approach makes no definitional assumption about what a nanotechnology book is, the outcome is a rather arbitrary list of books. This objection underestimates the power of the network approach and the actual interest focus of readers. Skeptics should be convinced, if not surprised, by taking a look at the resulting list of 34 books (see Table 1 below), of which as many as 30 include "nano" in their title. The remaining four are either about specific areas of advanced nanoscale research, i.e. molecular electronics (Tour, 2003), quantum dots (Turton, 1995), and microfabrication (Madou, 2002), or about more speculative nanotechnology (McCarthy, 2003).

2. The fact that people buy a book does not tell us anything about whether they actually read the book. While this is in fact a major shortcoming, it is difficult to imagine any effective method that measures the actual reading activity, particularly since the notion of reading includes a certain level of understanding. Thus, the same objection would apply, for 
instance, if one takes library loans as a measure for reading. It seems reasonable, however, to assume that there is a general correlation between buying books and reading them, as there is a correlation between lending books from a library and reading them, which future micro-sociological studies may clarify in more detail.

3. Buying books from an online bookstore is only one source of information, beside conventional bookstores, libraries, the Internet, and articles from journals, magazines, and newspapers, which are all neglected here. While the method of course cannot capture the full scope of public information, it aims only at identifying the public foci of interest and at capturing the connection between these foci. Unless detailed studies show that the public foci of interest and their connections differ considerably from information source to information source, it seems reasonable to assume that online co-purchase patterns of books are to some degree representative. Moreover, compared to the enormous efforts and time required by other methods, data collection for online purchase patterns is easy and fast and thus allows the analysis of current issues that would be impossible by other methods.

4. People who buy books from online bookstores are neither representative of the entire population nor a sociologically well-defined group. Here is another need for further sociological analysis to make the method more accurate. In the meantime we may assume, however, that customers of Amazon.com who buy more than one book on nanotechnology are North Americans with a general interest in science and technology that is clearly above the average level. Furthermore, since academicians are more used to going to their library than others are, they are supposed to be considerably underrepresented. Thus the "public" to be measured consists largely of people with a level of interest in science and technology that is clearly above average and below those of professionals, which is about the target group that research in the public understanding of science has been mainly concerned with.

5. Since online bookstores use the feature of "Customers-who-bought-this-book-alsobought-those-books" for encouraging new customers to do the same, the data obtained by the method are distorted by self-reinforcement. Yet, if an online bookstore successfully encourages customers to buy and read a book, it only helps shape an actual public interest. The method accurately measures the public interest no matter what factors, such as book reviews or advertisements, have contributed to its generation. It might be true, however, that, compared to data from conventional bookstores, the purchase patterns from online bookstores are more pointed by emphasizing strong links and de-emphasizing weak links, which can sometimes even be useful for the interpretation.

6. The method does not provide a quantitative picture of the network, because it does not consider different numbers of actual co-purchases, such that a hundred times of copurchasing books $\mathrm{A}$ and $\mathrm{B}$ is represented in the same manner as five instances of copurchasing books A and C. Obtaining quantitative data on the weight of links is indeed an important desideratum to further improve the method, and to use more mathematical tools from network theory. Thus far, one can only compare the sales ranks to make some semiquantitative guesses about the weight of each link.

7. Amazon.com lists only a maximum of the 20 most frequently co-purchased books for each title, which ignores further links. Such a limit seems reasonable, however, because for many books it is not even exhausted. Furthermore, the complexity of the network must be limited somehow to make a sensible analysis without bothering about any purchase coincidence, when, for instance, somebody buys one book for himself and another one as a birthday present for his wife. On the other hand, the method actually allows the collecting of more than 20 links of a book, if more than 20 books link to it, because co-purchase is a symmetrical relation. (We will see that for one Nanobook as many as 33 links have been recorded.) 
Finally, to avoid a possible misunderstanding, it is important to emphasize the difference between science and the public view of science, between the content of books and the public view of the books. Thus, whenever I speak in this paper, for reasons of brevity, of links or connections between two books or fields, this does not mean a direct or thematic link between these books or fields. If not otherwise indicated, it always means a link between books or fields as established by co-purchasing, which I interpret as a link of interest in the public view. Therefore, the network analysis (Section 3.1) provides information about readers and their interest foci rather than about the books, which is only provided by the additional content analysis in Section 3.2.

\section{The network of Nanobooks}

\subsection{Formal network analysis}

The network analysis as described in Section 2 provides a rather isolated and very dense cluster with fuzzy boundaries and relatively few links to its environment, which, as will be discussed in Section 4, consists of both non-fiction and fiction books. For transforming the fuzzy cluster into a definite set of books, there are many formal cut-off criteria available. A simple, and intuitively accessible, criterion is that each book must have a minimum number of links to other books of the resultant cluster. (In network analysis terminology, this is the $k$-core cohesion analysis (Seidman, 1983).) Applying the formal cut-off criterion that each book must have at least five links to other cluster books $(k=5)$ yields a list of 34 books, which in the following I call Nanobooks (Table 1), and the corresponding network the Nanobook Network.

Table 1. Nanobooks selected by formal network analysis

Bibliographic details

Amazon.com

sales ranks in

mid-March 2004

Antón, Ph.S., Silberglitt, R. and Schneider, J. (2001) The Global Technology Revolu-

228,999

tion: Bio/Nano/Materials Trends and Their Synergies with Information Technology by 20156. Santa Monica, CA: RAND Corp.

Atkinson, W.I. (2003) Nanocosm: Nanotechnology and the Big Changes Coming from the Inconceivably Small. New York: AMACOM/American Management Association.

Balzani, V., Venturi, M. and Credi, A. (2003) Molecular Devices and Machines: A Journey into the Nanoworld. Weinheim: Wiley-VCH.

Brenner, D., Lyshevski, S., Iafrate, G. and Goddard III, W.A. (eds.) (2002) Handbook of Nanoscience, Engineering, and Technology. Boca Raton, FL: CRC Press.

Crandall, B.C. (ed.) (1996) Nanotechnology: Molecular Speculations on Global Abundance. Cambridge, MA: MIT Press.

Drexler, K.E. (1986) Engines of Creation: The Coming Era of Nanotechnology. Foreword by Marvin Minsky. New York: Anchor Pr., Doubleday.

Drexler, K.E. (1992) Nanosystems: Molecular Machinery, Manufacturing, and Computation. New York: Wiley.

Edelstein, A.S. and Cammarat, R.C. (1998) Nanomaterials: Synthesis, Properties and Applications. Bristol: Institute of Physics (first edn, 1996).

Fishbine, G. (2002) The Investor's Guide to Nanotechnology and Micromachines. New York: John Wiley \& Sons.

Freitas, R.A. (1999) Nanomedicine, Vol. I: Basic Capabilities. Austin, TX: Landes Bioscience.

Goodsell, D.S. (2004) Bionanotechnology: Lessons from Nature. Hoboken: Wiley-Liss.

551,201

561,267

91,542

16,263

4,099

322,434

28,850

317,038

705,697 
Table 1. Continued

Bibliographic details

Amazon.com sales ranks in mid-March 2004

Gross, M. (1999) Travels to the Nanoworld: Miniature Machinery in Nature and 202,546 Technology. New York: Plenum Trade (expanded and updated translation of: Expeditionen in den Nanokosmos: die technologische Revolution im Zellmaßstab. Basel: Birkhäuser, 1995).

Harris, P.J.F. (2001) Carbon Nanotubes and Related Structures: New Materials for the 21st Century. Cambridge: Cambridge University Press (first edn, 1999).

Luryi, S., Xu, J. and Zaslavsky, A. (eds.) (2002) Future Trends in Microelectronics: The Nano Millennium. New York: John Wiley \& Sons.

Lyshevski, S.E. (2000) Nano- and Micro-Electromechanical Systems: Fundamentals of Nano- and Microengineering. Boca Raton, FL: CRC Press.

Madou, M.J. (2002) Fundamentals of Microfabrication: The Science of Miniaturization. Boca Raton, FL: CRC Press (first edn, 1997).

McCarthy, W. (2003) Hacking Matter: Levitating Chairs, Quantum Mirages, and the Infinite Weirdness of Programmable Atoms. New York: Basic Books.

Mulhall, D. (2002) Our Molecular Future: How Nanotechnology, Robotics, Genetics, and Artificial Intelligence Will Transform Our World. Amherst, NY: Prometheus Books.

Nalva, H.S. (ed.) (2002) Nanostructured Materials \& Nanotechnology. San Diego: Academic Press (condensed version of Handbook of Nanostructured Materials and Nanotechnology, 1999).

Newton, D.E. (2002) Recent Advances and Issues in Molecular Nanotechnology. Westport, CT: Greenwood Press.

Poole, Ch.P. and Owens, F.J. (2003) Introduction to Nanotechnology. New York: Wiley-Interscience.

Ratner, M.A. and Ratner, D. (2003) Nanotechnology: A Gentle Introduction to the Next Big Idea. Upper Saddle River, NJ: Prentice Hall.

Ratner, D. and Ratner, M.A. (2004) Nanotechnology and Homeland Security: New Weapons for New Wars. Upper Saddle River, NJ: Prentice Hall/PTR.

Regis, E. (1995) Nano. The Emerging Science of Nanotechnology. Boston: Little \& Brown.

Rieth, M. (2003) Nano-Engineering in Science and Technology: An Introduction to the World of Nano-Design. Hackensack, NJ: World Scientific.

Saito, R., Dresselhaus, M.S. and Dresselhaus, G. (eds.) (1998) Physical Properties of Carbon Nanotubes. London: Imperial College Press.

SciAmEd (eds) (2002) Understanding nanotechnology: From the editors of Scientific American. Compiled and with introduction by Sandy Fritz. New York, NY: Warner Books.

Timp, G.L. (1999) Nanotechnology. Berlin: Springer.

Tour, J.M. (2003) Molecular Electronics: Commercial Insights, Chemistry, Devices, Architecture and Programming. Hackensack, NJ: World Scientific.

Turton, R. (1995) The Quantum Dot: A Journey into the Future of Microelectronics. New York: Oxford University Press.

Uldrich J. and Newberry, D. (2003) The Next Big Thing is Really Small: How Nanotechnology Will Change the Future of Your Business. New York: Crown Business.

Waser, R. (ed.) (2003) Nanoelectronics and Information Technology: Advanced Electronic Materials and Novel Devices. Weinheim: Wiley-VCH.

Wilson, M., Kannangara, K., Smith, G., Simmons, M. and Crane, C. (2003) Nano-

508,962

174,494

39,906

103,246

557,746

782,987

903,917

78,823

technology: Basic Science and Engineering Technologies. Boca Raton, FL: Chapman \& Hall/CRC.

Ying, J. (ed.) (2001) Nanostructured Materials. San Diego, CA: Academic Press (paperback edn of Advances in Chemical Engineering, vol. 27). 


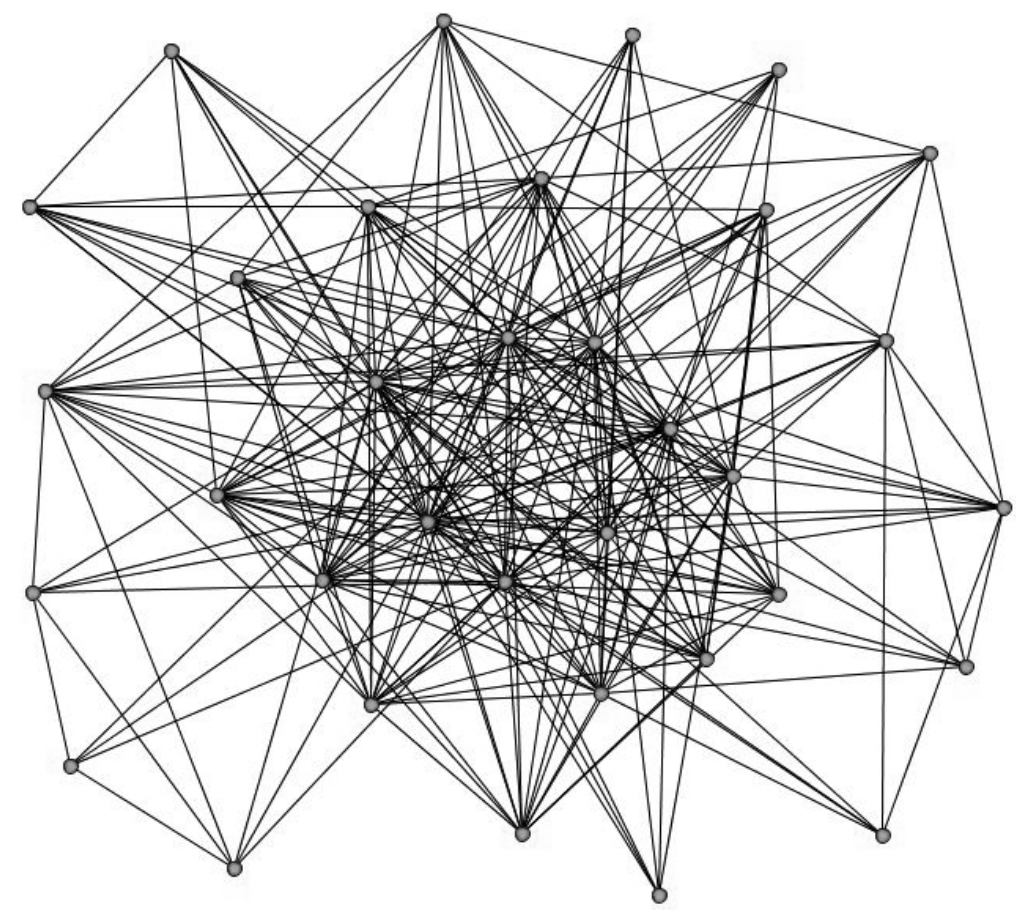

Figure 1. The Nanobook Network as a result of network analysis of co-purchase patterns of books and application of core cohesion analysis with $k=5$. Graphical representation is according to neighborhood degree such that adjacent nodes are placed as near to and non-adjacent nodes as far from each other as possible using the algorithm of Eades (1984).

The Nanobook Network consists of $N=34$ nodes and $L=259$ links, which is a very dense network, such that two-dimensional visualization becomes difficult (see Figure 1): of all possible $N \times(N-1)$ internal links, as many as 46 percent are actually realized; on average each Nanobook is directly linked to 15 other Nanobooks. There is even one Nanobook (SciAmEd, 2002) that has been purchased along with every other of the 33 Nanobooks, which in network analysis terminology is described by an egonet density of 1.0. To illustrate the relative closure of the Nanobook cluster, of all links between Network Nanobooks and any other books, about two-thirds are internal links inside the cluster, and only one-third of the links go outside (to be discussed in Section 4).

Within the cluster, Nanobooks vary in their numbers of links or neighborhood degrees from 5 to 33, which corresponds to a range of egonet densities from 0.15 to 1.0. As is obvious from Figure 1, the overall network contains an inner cluster that we need to isolate. Instead of just cutting it out, we need to apply the same algorithm of $k$-core cohesion analysis to identify the subnetwork of books that are highly interconnected and that make up the core of the Nanobook Network. Core cohesion analysis with $k=12$, i.e. searching for a subnetwork in which each book is connected to at least 12 other books, provides a highly connected subnetwork of 18 books (Figure 2), which in the following I call the Core 18 Network and the corresponding books Core18 books. The 18 books are connected to each other by 137 links, which are 90 percent of all possible links or 14.2 links per book on average, with a range of egonet densities from 0.76 to 1.0. To illustrate once more the relative closure of the Core 18 cluster, about 60 percent of all links between 


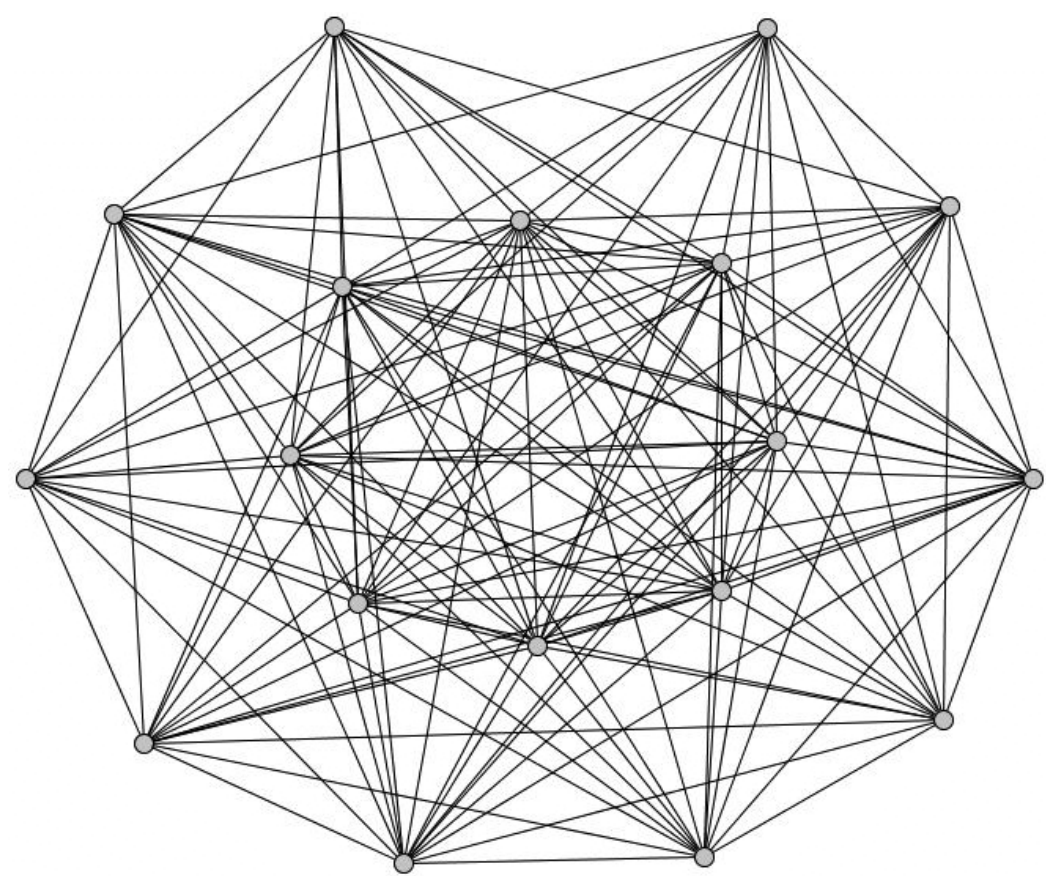

Figure 2. Core18 book cluster isolated from the Nanobook Network (see Figure 1) by core cohesion analysis with $k=12$.

Core18 books and any other book are internal Core18 cluster links, while a large part of the rest, though not all, reach out to Nanobooks. Thus, the inner cluster of the Core 18 books is clearly less closed within the network than the entire Nanobook cluster within the realm of all books.

Still there is structure, some inner core of the core that can be isolated. In fact, eight of the Core18 books stand out because they are fully connected to each other and have an egonet density of 1.0, so we can simply cut them out instead of applying again core cohesion analysis that would provide the same result. There is no more structure now, since each of the eight books is connected to every other, and I will call them Core 8 books in the following. Table 2 summarizes the results of the formal network analysis by listing the books that belong to the Core8, Core18, and Nanobook clusters.

\subsection{Characterization of the Nanobooks}

The formal network analysis described in Section 3.1 has made no assumption about what a book on nanotechnology is, nor about the type, quality, or importance of books. Save the arbitrary selection of one starting book, which happened to be Ratner and Ratner (2003), one needs to know nothing about nanotechnology to perform the analysis. Now let us see what the results are.

All network books are about nanotechnology; about one half is on nanotechnology in general while the other half is on more specific fields of nanotechnology. Those who are familiar with the field will recognize all the books of general importance among the Core 18 books, if not the Core 8 books, such as the two books by Drexler, who many consider foundational to nanotechnology, and the best-selling general introductions Ratner and 
Table 2. Nanobooks resulting from formal network analysis of co-purchase pattern

\begin{tabular}{lll}
\hline Core8 books & Additional Core18 books & Additional Nanobooks \\
\hline Crandall 1996 & Antón et al. 2001 & Balzani et al. 2003 \\
Drexler 1986 & Atkinson 2003 & Brenner et al. 2002 \\
Drexler 1992 & Fishbine 2002 & Edelstein \& Cammarat \\
Gross 1999 & Freitas 1999 & 1998 \\
Ratner \& Ratner 2003 & Mulhall 2002 & Goodsell 2004 \\
SciAmEd 2002 & Poole \& Owens 2003 & Harris 2001 \\
Uldrich \& Newberry & Ratner \& Ratner 2004 & Luryi et al. 2002 \\
2003 & Regis 1995 & Lyshevski 2000 \\
Wilson et al. 2003 & Rieth 2003 & Madou 2002 \\
& Turton 1995 & McCarthy 2003 \\
& & Nalva 2002 \\
& & Newton 2002 \\
& & Saito et al. 1998 \\
& & Timp 1999 \\
& & Tour 2003 \\
& & Waser 2003 \\
& & Ying 2001 \\
\hline
\end{tabular}

Ratner (2003) and SciAmEd (2002). This does not mean that there exist no other books on nanotechnology. In fact, many technical books on more specific research fields, but also some rather esoteric books, have been excluded by the first cut-off criterion, as they are not sufficiently linked to the network. ${ }^{9}$ It should be noted that the analysis does not aim at providing a complete book list, nor at a top selling list, which is only a spin-off (see the sales ranks in Table 1). Instead, it aims at identifying the books on nanotechnology that are in the focus of interest of the public, of those who buy not only a single book but several books to be informed about nanotechnology. And it aims at analyzing the structure of the public focus of interest.

Our network analysis finding that these books make up a relatively dense cluster of highly interconnected books with comparatively few links to the environment suggests that there is already a sharply developed public interest focus on nanotechnology. Interested readers are frequently newcomers to science and technology, which is indicated by the fact that they have not bought books from any of the related fields of science and technology. In other words, nanotechnology is not a side- or sub-field of interest of some larger area of interest. It has become a public focus of interest of its own by attracting people who had formerly little interest in science and technology. Let us have a closer look at what these relative newcomers actually read.

Although many of the books pretend to be some kind of introduction to nanotechnology, both the entire network as well as the Core 18 books show a great diversity in almost every respect one can think of. To start with the most obvious, Nanobooks of current interest have been published from as early as 1986 (Drexler, 1986) to as late as 2004 (Ratner and Ratner, 2004). Their Amazon.com sales ranks range from 1,672 (Ratner and Ratner, 2003) to 903,917 (Tour, 2003). They include single- and multi-authored monographs, anthologies, and even a report prepared by the National Defense Research Institute (RAND) for the National Intelligence Council (Antón et al., 2001). Authors differ greatly in their scientific background and profession, including internationally distinguished university professors, employees of governmental research institutes, members of non-profit organiza- 
tions, professional science journalists, freelance writers with or without a science or engineering degree, employees and entrepreneurs in private business with a science or engineering degree (mostly in computer science), and business consultants. Correspondingly, their intended audiences, as indicated in the introductions or by their content, range from fellow scientists and engineers to national agencies or politicians, from scientifically well-educated general readers to scientific illiterates, to potential investors in the "next big thing." The books differ not only in the use or avoidance of mathematics, scientific diagrams, scientific terminology, and references to the technical literature, but also significantly in the style of language, as the following two quotations exemplify.

With man's ability first to see, then understand, and finally operate at the nanoscale all become feasible. . . . Nanotechnology is going to be big. (Uldrich and Newberry, 2003: $33,13)$

With the Hartree-Fock method proper anti-symmetric and permanently ortho-normal wave functions have been introduced into the Hartree scheme by arranging the single electron wave functions-including electron spin s-in the way of the Slater's determinant. (Rieth, 2003: 9)

It should be noted again that these diverse books are not grouped together because they fall into some obscure category, but because people actually buy them together due to their interest in nanotechnology.

To bring some order into the material, Nanobooks can be divided in two classes, each consisting of two sub-classes. Nanobooks either focus on current or recent developments in nanoscale research (Class I) or they attempt to forecast what future nanotechnology will look like and how it will change society (Class II). Even though Class I books usually contain some outlook chapter and Class II books usually include some historical narrative and present day examples, the focus of each book leaves no doubt to which class it belongs. ${ }^{10}$ Furthermore, Class I books can be divided as to whether they are written for fellow scientists, graduate students, or at least scientifically very well-educated readers (Class I.1) or for a general audience with only a secondary or high school education in science (Class I.2). Again, the difference is so clear that borderline cases are absent. ${ }^{11}$ Class II books, which are as a rule comprehensible by a general readership, ${ }^{12}$ can be divided into whether they forecast general technological and societal developments (Class II.1) or focus on business developments and investor opportunities (Class II.2).

The classification of the Core 18 books (see Table 3 and Figure 3 ) shows that the public focus of interest in nanotechnology is on forecasting or futurology (10 books) rather than on the actual research that has been done (eight books). If we consider only the books that are comprehensible by a general readership (i.e. classes I.2, II.1, and II.2), more than threequarters (77 percent) of these books are about how the future might look. In addition, and due to multi-authorship, of the three general introductions, SciAmEd (2002) includes much forecasting and Ratner and Ratner (2003) includes a chapter on "nanobusiness." There are more books on future business opportunities in nanotechnology ${ }^{13}$ than books that competently and comprehensibly introduce a general reader to the current state of research, which only Gross (1999) and Ratner and Ratner (2003) really do, since SciAmEd (2002) is only a small collection of essays from different authors and of varying style and quality. ${ }^{14}$ Since these "business guides" belong to the core of the Nanobook Network and are quite disconnected from the general network of business books (see Section 4.1), they are read by people interested in nanotechnology rather than in business. Given their comparatively high 
Table 3. Classification of Nanobooks

\begin{tabular}{|c|c|c|c|c|}
\hline & \multicolumn{2}{|c|}{ Current and recent research (1) } & \multicolumn{2}{|l|}{ Forecasting (II) } \\
\hline & Advanced (I.1) & Basic (I.2) & General (II.1) & Business (II.2) \\
\hline Core 18 books & $\begin{array}{l}\text { Drexler } 1992 \\
\text { Freitas } 1999 \\
\text { Poole \& Owens } \\
2003 \\
\text { Rieth } 2003 \\
\text { Wilson et al. } \\
2003\end{array}$ & $\begin{array}{l}\text { Gross } 1999 \\
\text { Ratner \& Ratner } \\
2003 \\
\text { SciAmEd } 2002\end{array}$ & $\begin{array}{l}\text { Antón et. al. } 2001 \\
\text { Crandall } 1996 \\
\text { Drexler } 1986 \\
\text { Mulhall } 2002 \\
\text { Ratner \& Ratner } \\
2004 \\
\text { Regis } 1995 \\
\text { Turton } 1995\end{array}$ & $\begin{array}{l}\text { Atkinson } 2003 \\
\text { Fishbine } 2002 \\
\text { Uldrich \& } \\
\text { Newberry } 2003\end{array}$ \\
\hline $\begin{array}{l}\text { Additional } \\
\text { network books }\end{array}$ & $\begin{array}{l}\text { Balzani et al. } \\
2003 \\
\text { Brenner et al. } \\
2002 \\
\text { Edelstein \& } \\
\text { Cammarat } 1998 \\
\text { Goodsell } 2004 \\
\text { Harris } 2001 \\
\text { Lyshevski } 2000 \\
\text { Madou } 2002 \\
\text { Nalva } 2002 \\
\text { Saito et al. } 1998 \\
\text { Timp } 1999 \\
\text { Tour } 2003 \\
\text { Waser } 2003 \\
\text { Ying } 2001\end{array}$ & Newton 2002 & $\begin{array}{l}\text { Luryi et al. (ed.) } \\
2002 \\
\text { McCarthy } 2003\end{array}$ & \\
\hline
\end{tabular}

sales ranks, these "business guides" essentially influence the public understanding of nanotechnology, despite their extremely poor coverage of the actual research, to say nothing about the authors' scientific understanding which, as "business guide" writers, they need not necessarily have. ${ }^{15}$

Compared to the Core18 books, the complete network of 34 Nanobooks includes 13 additional technical books in specific fields of nanotechnology (mainly textbooks, handbooks, conference proceedings or anthologies on certain materials, electronics, and microelectromechanical systems (MEMS)), two more books on general forecasting, and one more generally accessible introduction (Newton, 2002), which is hardly more than a quick compilation of data and documents easily available on the Internet. Thus, the Nanobook Network differs from the Core 18 books mainly by having a majority of technical literature (see Figure 3), which as we will see connects the Nanobook Network to the larger science and engineering book networks. Among the generally comprehensible books (classes I.2, II.1, and II.2), however, there is little difference between the Core18 books and the entire Nanobook Network: the relative weight of "business guides" as well as the proportion of forecasting books in general are about the same.

Since more than half of the network books are competent descriptions of the state of research in various fields of nanotechnology, one might think this compensates for the visionary futurology of the rest in order to provide readers with a balanced view. After all, the network describes not simply the scope of existing books but co-purchase patterns such that those who buy futurology also buy scientific textbooks. There is a fundamental asymmetry, however. Scientists who are used to reading textbooks may also read futurology 


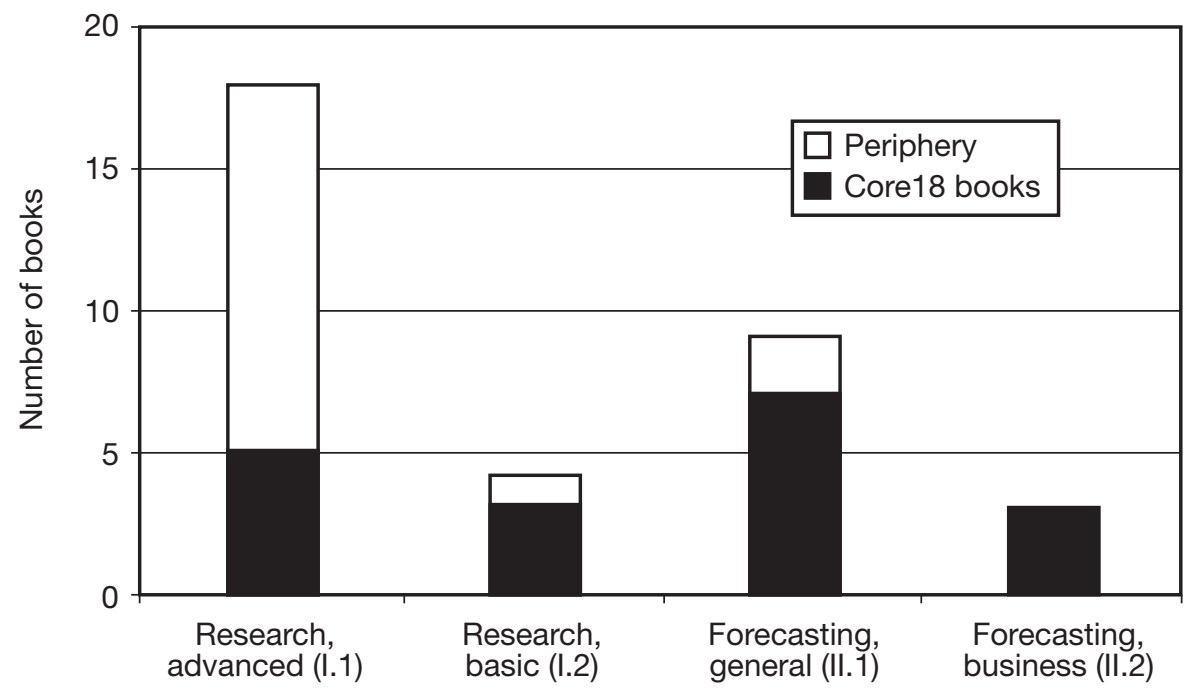

Figure 3. Classification of Nanobooks for Core18 and periphery books (see Table 3).

and "business guides" in order to broaden their scope, which, as we will see in Section 4.1, they do not very much, however. For non-scientists, on the other hand, Class I.1 books, even if they buy them, as they occasionally seem to do, are incomprehensible. I assume that some Class I.1 books are attractive only because of their titles. For example, Nano-Engineering in Science and Technology: An Introduction to the World of Nano-Design (Rieth, 2003), is an entirely misleading title, even for scientists, because that book is actually on computational nanotechnology and deals mostly with quantum chemistry and algorithms for molecular dynamics.

In sum, the public, eager to learn about nanotechnology, is faced with a jungle of Nanobooks of great diversity, which they actually buy without much distinction according to the co-purchase pattern. If they overcome their frustration with the majority of technical literature, they may come across the remaining generally comprehensible books. Threequarters of these books are futuristic narratives in which authors express their opinions or hopes of what nanotechnology or "nanobusiness" will do in the future and what investments they should make. Only four books formally qualify as general introductions to nanotechnological research, of which only two books ( 5 percent of the network books) can safely be said to meet this task, although one (Gross, 1999, first edition 1995) would need some updating and is less on technology than on science. It speaks for the smartness of buyers, however, that the other one (Ratner and Ratner, 2003) has in fact the highest sales rank of all Nanobooks.

We currently have both a tremendous public interest in nanotechnology and a large supply of books on the market. It is doubtful, however, if this matching of supply and demand leads to a better public understanding of science and technology overall. The dominating supply of futurology books rather suggests that public ideas of science and technology become more removed from the actual research and more identified with the readers' personal hopes and fears, such as immortality, super-weapons, health, and wealth, all of which are the real topics of Class II books. In the next section we will see that this is also what general readers are mostly interested in. 


\section{Links to the outer book world}

\subsection{Links to non-fiction}

As was shown in Section 3.1, the Nanobook Network is a relatively closed cluster within the realm of all books, which means there is a relatively sharp public focus on nanotechnology that does not reach out much beyond. This suggests that only a few readers have other comparable interests and that the majority are newcomers to reading books on science and technology. Yet, there are also links to the outer book world; in fact a third of all the links of Nanobooks reach outside of the network. This section attempts to understand how nanotechnology is connected in the public view by exploring to which other fields these links connect. Following an established distinction, I discuss links to non-fiction books and links to fiction in different sections.

The empirical data for the following discussion are based on a classification of the books that have been co-purchased with Nanobooks without being Nanobooks. It is a classification according to standard disciplines and fields on the basis of the information provided by the online bookstore and sometimes on actual reading. Since books related to nanotechnology that are not part of the network are usually on very specific research of one or other discipline or belong to the general field of futurology, they were classified accordingly.

Table 4 provides the data of the classification, according to both the specific and general fields to which the Nanobooks link, and lists the Nanobooks that link mainly to each of these fields. Roughly speaking, about a third of the links go each to the general fields of science, engineering, and the combined category of forecasting and fiction. If we look at what kinds and classes of Nanobooks refer to books in these categories, there is a clear division. Most of the Nanobooks that are, in the foci of the readers' interests, linked to science and engineering belong to Class I.1 books at the periphery of the Nanobook Network. On the other hand, Nanobooks that are linked to forecasting and fiction are mostly of Class II and all belong to the Core18 books, save McCarthy (2003).

The result is less surprising, however, if we consider different readerships according to different interest patterns. All the books on science and engineering to which Nanobooks link are technical books comprehensible only by scientists and engineers, like the Class I.1 Nanobooks. It is very unlikely that a general reader of Nanobooks feels inspired to read, say, a textbook on condensed matter physics. Thus we may assume that most of these links are established by expert readers. If this is true, however, it also follows from the symmetry of the co-purchase relation that expert readers have little inclination to read Class II books. The only exception here is the field of Computer Science and Artificial Intelligence/Life (AL/ AI), which is obviously linked to the forecasting Nanobooks (Class II.1) in the public interest.

Among the forecasting literature, it is less surprising that the only links to business books are from nanobusiness books (Class II.2). What is remarkable, however, is the small number of links from nanobusiness books to other business books, which almost equals their number of links to the general futurology literature. In the readers' interests, a book called The Investor's Guide to Nanotechnology and Micromachines (Fishbine, 2002) has no connection at all to other investor guides. In fact, the three nanobusiness books are such an integral part of the Nanobook Network-two of them are even Core18 books-that their links to the outer book world are marginal. Instead, because of their easy comprehensibility, they serve as major introductions to nanotechnology for the public (see Section 3.2). 
Table 4. Classification of links from nanobooks to other fields

\begin{tabular}{|c|c|c|c|c|}
\hline Field linked to & Number & Mostly linked from (book class) & General field & Number \\
\hline Physics & 27 & $\begin{array}{l}\text { Saito et al. } 1998 \text { (I.1) } \\
\text { Turton } 1995 \text { (II.1, Core18) } \\
\text { Balzani et al. } 2003 \text { (I.1) }\end{array}$ & Science & $46(31 \%)$ \\
\hline Chemistry & 16 & $\begin{array}{l}\text { Balzani et al. } 2003 \text { (I.1) } \\
\text { Ying } 2001 \text { (I.1) }\end{array}$ & & \\
\hline Biomedical sciences & 3 & Freitas 1999 (I.1, Core 18) & & \\
\hline MEMS/electr. engineering & 34 & $\begin{array}{l}\text { Madou } 2002 \text { (I.1) } \\
\text { Waser } 2003 \text { (I.1) } \\
\text { Lyshevski } 2000 \text { (I.1) }\end{array}$ & Engineering & $51(34 \%)$ \\
\hline Robotics/mech. engineering & 8 & Madou 2002 (I.1) & & \\
\hline $\mathrm{AI} / \mathrm{AL}$ and computer science & 9 & $\begin{array}{l}\text { Antón et al. } 2001 \text { (II.1, Core18) } \\
\text { Drexler } 1986 \text { (II.1, Core18) }\end{array}$ & & \\
\hline Futurology & 32 & $\begin{array}{l}\text { Mulhall } 2002 \text { (II.1, Core18) } \\
\text { Regis } 1995 \text { (II.1, Core18) } \\
\text { McCarthy } 2003 \text { (II.1) } \\
\text { Ratner \& Ratner } 2004 \text { (II.1, Core18) } \\
\text { Uldrich \& Newberry } 2003 \text { (II.2, Core18) } \\
\text { Fishbine } 2002 \text { (II.2, Core18) } \\
\text { Gross } 1999 \text { (I.2, Core18) }\end{array}$ & Forecasting & $38(25 \%)$ \\
\hline Business guides & 6 & $\begin{array}{l}\text { Uldrich \& Newberry } 2003 \text { (II.2, Core18) } \\
\text { Atkinson } 2003 \text { (II.2, Core18) }\end{array}$ & & \\
\hline Nano-science fiction & 8 & $\begin{array}{l}\text { Drexler } 1986 \text { (II.1, Core18) } \\
\text { Mulhall } 2002 \text { (II.1, Core18) } \\
\text { SciAmEd } 2002 \text { (I.2, Core18) } \\
\text { McCarthy } 2003 \text { (II.1) }\end{array}$ & Fiction & $15(10 \%)$ \\
\hline General science fiction & 7 & McCarthy 2003 (II.1) & & \\
\hline
\end{tabular}

Most forecasting books on nanotechnology (Class II), whether business oriented or not, have strong ties to other futurology books. Because these Nanobooks both are generally comprehensible and, with the exception of McCarthy (2003) to be dealt with in Section 4.2, are all Core 18 books, they are particularly important for shaping the public understanding of nanotechnology. And because, among the generally comprehensible Nanobooks, the link to futurology is by far the dominating one to the outer book world, if not the only one worth mentioning, it is important to follow this link more closely in order to understand what general readers associate with nanotechnology. Table 5 lists the seven books that people purchase most along with generally comprehensible Nanobooks.

With the exception of the first book, which is a collection of essays from various authors on different topics, these books have a single theme. They forecast a future in which machines, either computers or computerized robots, radically change the physical and mental conditions, and thereby also the social conditions, of human beings, sometimes to the extent that the difference between machines and human beings dissolves. While some of these books have a critical attitude, and thus play with the fears of their readers, other authors rather embrace the hopes of Transhumanists, a quasi-religious sect that longs for salvation in the state when humans overcome their "physical imperfection" by dissolving into machines. Whether or not that is in any way related to the actual research in nanotechnology - which includes a large variety of different fields from nanoparticles and nanocomposites to MEMS - this is what the public associates most with nanotechnology and what is supposed to determine the public debate about nanotechnology. 
Table 5. Books that most frequently linked to generally comprehensible nanobooks

Brockman, J. (ed.) (2002) The Next Fifty Years: Science in the First Half of the Twentyfirst Century. New York: Vintage.

Kurzweil, R. (1999) The Age of Spiritual Machines: When Computers Exceed Human Intelligence. New York: Viking.

Broderick, D. (2001) The Spike: How Our Lives Are Being Transformed By Rapidly Advancing Technologies. New York: Forge.

Moravec, H.P. (2000) Robot: Mere Machine to Transcendent Mind. New York: Oxford University Press.

Regis, E. (1991) Great Mambo Chicken and the Transhuman Condition: Science Slightly over the Edge. Reading, MA: Addison-Wesley.

Paul, G. and Cox, E. (1996) Beyond Humanity: Cyberevolution and Future Minds. Rockland, MA: Charles River Media.

Brooks, R. (2002) Flesh and Machines: How Robots Will Change Us. New York: Pantheon Books.

\subsection{Links to science fiction}

Science fiction novels that employ in their plots the technological capacities that futurologists and visionaries claim to be the future of nanotechnology have been on the market for at least two decades. Within the genre of science fiction, nano-science fiction is a booming field; an online bibliography currently lists more than 280 titles in English alone (Napier, 2003). The parallel rise of both nano-science fiction, on the one hand, and the visionary and popular books about nanotechnology, on the other, prompts the question of how these two fields are connected in the view of the public. Are readers of popular nanotechnology books inspired to buy nano-science fiction and vice versa?

Although the modern distinction between fiction and non-fiction becomes increasingly blurred by the emerging field of visionary literature, in terms of the technology described and its impact on society (Milburn, 2002), an important distinction between their narrative styles still remains. While visionaries claim to describe possible or likely future scenarios, and thus make epistemic claims, science fiction authors explicitly refuse to do so. Their plots are intentionally invented, which is usually indicated in the books, and they leave it up to their readers to decide whether the futuristic technology is likely to come or not. Furthermore, science fiction novels are stories featuring certain characters that interact in various ways in the course of the plot, and the futuristic technology employed is only instrumental in that it provides new contexts and dimensions to the interaction of the characters. Despite journalistic attempts at framing descriptions of current or future technology with personal stories, the narrative style of and the focus on stories is just missing in popular and visionary Nanobooks. In short, while the technology is only instrumental to the stories in science fiction, the stories are only instrumental to describing technology in popular and visionary Nanobooks.

The distinction is well reflected in co-purchase patterns. In fact, none of the 34 Nanobooks belongs to the genre of science fiction proper. On the other hand, co-purchase patterns of science fiction books, which are a much bigger market, reveal no particular subnetwork structure for nano-science fiction books. Instead, the whole field of science fiction books makes up a rather closed network of its own. Readers do not care much about whether the futuristic technology employed in the story is nano or not, such as science fiction authors sometimes employ futuristic nanotechnology in their novels and sometimes not. Science fiction readers appear rather like collectors, either by co-purchasing other books 
of the same author or by co-purchasing other science fiction novels that come out at the same time.

Although Nanobooks and science fiction novels make up two rather closed and separated networks, in terms of their readership, there are some interesting links between them. Of the Nanobooks only four books, of which three are also Core18 books, are directly connected to science fiction (Drexler, 1986; Mulhall, 2002; McCarthy, 2003; SciAmEd, 2002), and while the first three books stand out because of their particularly visionary content, the last one certainly does not. It is well-known among science fiction experts ${ }^{16}$ that Drexler's early, if not founding, vision of nanotechnology in Drexler (1986) essentially inspired not only scientists and futurologists but also many science fiction writers. Given the comparable impact on futurology, it is likely that also Mulhall's even broader and more speculative visions, in Our Molecular Future: How Nanotechnology, Robotics, Genetics, and Artificial Intelligence Will Transform Our World, have a similar effect on science fiction. The fact that Understanding Nanotechnology, written by authors of the popular science magazine Scientific American, also attracts science fiction readers may be due to the didactic appeal of the book and its title. There is indeed a great need for understanding what nanotechnology is all about, among both non-fiction readers and science fiction readers, and this book appears to give both well-founded and easily accessible answers.

There is a fourth Nanobook, McCarthy (2003), that links not only to nano-science fiction but also to seven other science fiction novels as well as to futurology as mentioned in Section 4.1 (see Table 4). The particular bridging status of McCarthy (2003) becomes clear by a closer look at the exceptional author and his remarkable book. In fact, Will McCarthy has been a prolific science fiction writer who published at least six novels before Hacking Matter, most of which belong to its co-purchase pattern. In addition, he has been a journalist who published articles in such diverse journals as Wired, Science Fiction Weekly, and Nature. During his earlier writing of novels, he also pursued a career as a software and systems engineer at Lockheed Martin, before he became a full-time writer and an entrepreneur. Hacking Matter combines all the four qualities of the author: the first part, written in a journalistic didactic style, introduces general readers to the field of quantum dots (chapters 1-5). In the second part, McCarthy, the engineer and entrepreneur, describes his own patent application for a specific kind of "programmable matter," in both journalistic and technical style (Chapter 6 and Appendix B). Finally, in the third part, he waxes very speculatively about the abundance of future applications of his invention in a science fictionlike style (chapters 7 and 8). McCarthy (2003) exemplifies two interesting general phenomena. First, there is an increasing part of texts on nanotechnology with strong futuristic components for a general audience that are authored by entrepreneurs in software engineering, who are not particularly involved in any nanotechnological research field up to now. Second, border-crossing authors have an impact on blurring the boundary between fiction and non-fiction regarding the interest foci of readers.

Among the science fiction books, there are only three books that are directly connected to the Nanobook Network and which greatly differ in type: Michael Flynn's The Nanotech Chronicles (Flynn, 1991) is a collection of stories by the author; Nanotech is a collection of stories by various authors (Dann and Dozois, 1998); and Nano is a novel by John Robert Marlow (Marlow, 2004). What they all have in common, however, is the term "Nano" in their titles, unlike the titles of most other nano-science fiction books. This suggests that readers of Nanobooks, who are as we have seen not always very selective regarding the kind of Nanobooks they purchase, are tempted to transcend the boundary between non-fiction and fiction merely by book titles. ${ }^{17}$ On the other hand, Marlow, before his fiction debut with Nano, which incidentally includes lengthy passages in didactic non-fiction style, wrote 
journalistic texts about science. Thus, this book may count as a second example of how the boundary between fiction and non-fiction blurs through border-crossing authors.

Finally, the lack of further links also suggests that readers of nano-science fiction do not care about the related science and technology and whether the futuristic scenarios are scientifically plausible or not. This is true not only of the most advanced nano-science fiction novels, such as Neal Stephenson's The Diamond Age (Stephenson, 1995), Kathleen Goonan's quartet of nano-science fiction novels, or Greg Bear's books from the late 1980s and 1990s, but also of Michael Crichton's recent horror-science fiction novel, Prey, which is being made into a Hollywood movie that may have an impact on the public view of nanotechnology (Crichton, 2002). In fact, despite its non-fiction appendix with references to the scientific literature, the co-purchase pattern of Prey shows not a single direct link to any non-fiction book whatsoever, and it is only indirectly connected, through Nanotech (Dann and Dozois, 1998), to Nanobooks. Should the forthcoming movie have the disastrous impact on the public opinion of nanotechnology that many in the field are afraid of, it is very unlikely that this will in any way be corrected by the reading of non-fiction Nanobooks.

\section{Conclusion}

This paper has introduced a new method for research in the public understanding of science, by using co-purchase book data from an online bookstore to be subject to formal network analysis and combined with traditional content analysis. Applied to the fuzzy field of nanotechnology, the method is successful in identifying the books that the public reads to be informed about nanotechnology, in distinguishing between different kinds and classes of books and thereby between different interest foci and readerships, and in identifying the public's interest relations between nanotechnology and other fields.

The relatively closed cluster of nanotechnology books suggests that there is a sharp public focus of interest in nanotechnology and a great demand for information. For many readers, who do not have a purchase record of other science and technology books, nanotechnology seems to be the first field of science and technology in which they invest a considerable interest by buying a bunch of books. This readership can be distinguished from a minority of expert readers who come to nanotechnology from various specific nanoscale research fields. The general reader, however, is confronted with a great variety of books on nanotechnology that differ in almost every respect and that include both very technical books and generally accessible ones. Among the books that are generally comprehensible and that are the only ones that are likely to be read and understood by a broader public, the overwhelming majority (75 percent) are not about the actual research but about forecasting, about hopes and fears regarding future nanotechnology and about investment opportunities. Because of the very small number of books that competently and comprehensibly introduce general readers to current and recent research, it is this futuristic literature of various qualities that shapes the public view of nanotechnology more than anything else. Furthermore, in the interest pattern of general readers, nanotechnology is mostly linked to futuristic scenarios about the dissolution of the human/machine distinction, of both the frightening and the salvation-promising sort, such that the supply of futuristic literature matches its public demand. Although such topics are shared by the rapidly growing number of nano-science fiction novels, the public's interest foci in nano-fiction and in non-fiction are still quite separated, but become increasingly connected by border-crossing authors.

Compared to authors of other general books on science and technology, who are mostly scientists or science journalists, new types of authors emerge in the area of nanotechnology. 
Besides authors who write both fiction and non-fiction, there are surprisingly many business consultants and entrepreneurs, both of which are likely to be investing in some kind of future nanotechnology. It is obvious that most of the entrepreneur-authors come from software engineering, which has at this point no particular relation to nanotechnological research more than to any other field of science and engineering. ${ }^{18}$ Unlike matter in the actual research, matter in the software developers' visions of "programmable matter" is perfectly controllable by software, such that scientists and engineers, who are used to dealing with the intricate complexities of the material reality, become redundant and are replaced with software developers. It is this truly idealistic and deeply unscientific vision that, along with the business perspective, pervades the forecasting Nanobooks and thereby infiltrates the public understanding of nanotechnology.

\section{Acknowledgement}

Support for this work was provided by the National Science Foundation as part of the NIRT award on "Philosophical and Social Dimensions of Nanoscale Research" at the University of South Carolina and by the Deutsche Forschungsgemeinschaft by granting a Heisenberg Scholarship to the author. I am grateful to two anonymous referees for valuable suggestions.

\section{Notes}

1 See, for instance, the definition of the US Committee on Nanoscale Science, Engineering and Technology (NSET, 2000).

2 Most substances have crystallographic unit cell lengths greater than 1 nanometer. Compare, for instance, the lengths of the celebrated nanosubstance buckminsterfullerene or $\mathrm{C}_{60}(1.4 \mathrm{~nm})$ with simple substances such as glucose $(1.48 \mathrm{~nm})$ or gypsum $(1.52 \mathrm{~nm})$; for more details, see Schummer (2004b).

3 For reviews of the most common approaches, see Pardo and Calvo (2002) and Felt (2002).

4 At the recent interdisciplinary conference, co-organized by the author, on "Imaging and Imagining NanoScience and Engineering," Columbia, SC, 3-7 March 2004, four papers dealt with the media coverage of nanotechnology: Lewenstein and Radin (2004), Stephens (2004), Anderson et al. (2004) and Miller and Macnaghten (2004).

5 Major journals of the fields are Journal of Mathematical Sociology (since 1971) and Social Networks (since 1979); earlier journals, launched in the 1930s, include Sociometry and Psychometrika. The mathematical approach goes back to topology and graph theory.

6 For social network analysis, see Wasserman and Faust (1994) and Scott (1994). For bibliometrics, see Cronin and Atkins (2000) and Borgman (1990).

7 Online use of the software and a free trial version for local computers are available from http:/ /www.netminer.com

8 See, for instance, Anonymous (2003).

9 The only surprise, at least to me, is that a visionary book co-authored by Drexler has been cut off (Drexler et al., 1991). However, its sales rank $(410,667)$ indicates that it is rarely read and then only in relative isolation, because its co-purchase number is only 6 , of which only three are Nanobooks.

10 The only difficult cases are perhaps Drexler (1992) and Freitas (1999), which both deal with technological feasibilities by exploring current scientific theories in a very technical manner so that they rather belong to Class I.1.

11 Although at first glance, for instance, Ratner and Ratner (2003) and Poole and Owens (2003) appear to be similar according to their book titles and the backgrounds of their authors, only the second book uses largely mathematical formalism, data tables, and scientific diagrams typical of advanced textbooks and research papers and completely incomprehensible without a solid background in quantum mechanics and condensed matter physics. More of an introduction to readers with at least a solid background is Wilson et al. (2003).

12 The only obvious exception is Luryi et al. (2002), which is a conference proceedings on Future Trends in Microelectronics, with papers of different reading levels.

13 A fourth "nanobusiness guide" available from Amazon, which has no links and thus is not part of the network and which I could not obtain, seems to be a book authored by D. Shafer (NanoTech MegaQuake, New York: 
John Wiley \& Sons, 2003). The author is known from software development rather than from nanotechnology or business.

14 To provide a sample of the obvious rhetoric in this booklet, Gary Stix in his essay "Little Big Science" knows that "If Einstein were a graduate student today probing for a career path, a doctoral adviser would enjoin him to think small: 'Nanotech, Albert, nanotech' would be the message conveyed" (SciAmEd, 2002: 6).

15 However, even possible investors should better not take these books too seriously. To provide but one example: Fishbine (2002), with his investor's definition of nanotechnology ("If you need a microscope to see the details, it must be nanotechnology" (p. 5)) gives detailed investment advice on such fancies as "brownian motors" (pp. 104-05), while completely ignoring the already flourishing fields of nanoparticles and nanocomposite materials.

16 Brooks Landon (5 March 2004, personal communication). At the very end of the collection of nano-science fiction stories Nanotech (Dann and Dozois, 1998), which is actually one of the books linked to the Nanobook Network (see below), Drexler (1986) is even recommended for further reading.

17 On the other hand, Steven Piziks' The Nanotech War (Star Trek Voyager) (published by Star Trek in 2002) shows no first- or second-order link to the Nanobook cluster, despite "Nanotech" in its title. The corresponding movie series is probably too well-known to leave any doubt for potential readers about its content.

18 In fact, among current research papers in nanotechnology and nanoscience, only 0.8 percent have an author from the broader field of information and computer science (Schummer, 2004a). Interestingly, in Michael Crichton's (2002) nano-science fiction novel Prey, software developers come to lead nanotechnology after years of frustration and unemployment following the "dot-com bubble."

\section{References}

Anderson, A., Allan, S. and Petersen, A. (2004) "Pictorial and Textual Representations of Nanotechnology in the UK Press. Media images of nanotechnology," Paper presented at the conference Imaging and Imagining NanoScience and Engineering, Columbia, SC, 3-7 March.

Anonymous (2003) "Amazon.com and the Librarian: Amazon.com Can Be a useful Citation Verification Tool for Reference and Collection Development," MLA News-Medical Library Association no. 352: 11.

Borgman, C.L. (ed.) (1990) Scholarly Communication and Bibliometrics. Newbury Park: SAGE.

Crichton, M. (2002) Prey. New York: Harper Collins.

Cronin, B. and Atkins, H.B. (eds.) (2000) The Web of Knowledge: A Festschrift in Honor of Eugene Garfield. Medford, NJ: Information Today.

Dann, J. and Dozois, G. (eds.) (1998) Nanotech. New York: Ace Books.

Drexler, K.E., Petersen, C. and Pergamit, G. (1991) Unbounding the Future: The Nanotechnology Revolution. New York: Morrow.

Eades, P. (1984) "A Heuristic for Graph Drawing," Congressus Numerantium 42: 149-60.

Eakin, E. (2004) "Study Finds a Nation of Polarized Readers," New York Times 13 March.

Felt, U. (2002) "Conceptualising the Relationships between Sciences and Publics," in U. Felt (ed.) Optimising Public Understanding of Science and Technology: Final Report, Chapter 1. Vienna: University of Vienna. URL: http://www.univie.ac.at/virusss/OPUSReport/index.html

Flynn, M. (1991) The Nanotech Chronicles. Riverdale, NJ: Baen Books.

Krebs, V. (1999) "The Social Life of Books: Visualizing Communities of Interest via Purchase Patterns on the WWW." URL: http://www.orgnet.com/booknet.html

Krebs, V. (2003) "Divided We Stand???” URL: http://www.orgnet.com/leftright.html

Krebs, V. (2004) “Divided We Stand . . Still.” URL: http://www.orgnet.com/divided.html

Lewenstein, B.V. and Radin, J. (2004) "Media Images of Nanotechnology," Paper presented at the conference Imaging and Imagining NanoScience and Engineering, Columbia, SC, 3-7 March.

Marlow, J.R. (2004) Nano. New York: Forge.

Milburn, C. (2002) "Nanotechnology in the Age of Post-human Engineering: Science Fiction as Science," Configurations 10: 261-95.

Miller, P. and Macnaghten, P. (2004) "Small Stories: Developing a Framework for the Public Imagination of Nanotechnology. Media Images of Nanotechnology," Paper presented at the conference Imaging and Imagining NanoScience and Engineering, Columbia, SC, 3-7 March.

Napier, A.S. (2003) "Nanotechnology in Science Fiction." URL: http://www.geocities.com/asnapier/nano/n-sf/

NSET (US Committee on Nanoscale Science, Engineering and Technology) (2000) "Nantoechnology Definition." URL: http://www.nsf.gov/home/crssprgm/nano/omb_nifty50.htm

NSTC (National Science and Technology Council) (2000) National Nanotechnology Initiative: The Initiative and its Implementation Plan. Washington, DC, p. 13. URL: http://www.nano.gov/html/res/nni2.pdf 
Pardo, R. and Calvo, F. (2002) "Attitudes toward Science among the European Public: a Methodological Analysis," Public Understanding of Science 11: 155-95.

Schummer, J. (2004a) "Multidisciplinarity, Interdisciplinarity, and Patterns of Research Collaboration in Nanoscience and Nanotechnology," Scientometrics 59: 425-65.

Schummer, J. (2004b) "Interdisciplinary Issues of Nanoscale Research," in D. Baird, A. Nordmann and J. Schummer (eds.) Discovering the Nanoscale, pp. 9-20. Amsterdam: IOS Press.

Scott, J. (1994) Social Network Analysis: a Handbook. London: SAGE.

Seidman, S. (1983) "Network Structure and Minimum Degree," Social Networks 5: 269-87.

Stephens, L.F. (2004) "News Narratives about Nano: How Journalists and the News Media Are Framing Nanoscience and Nanotechnology Initiatives and Issues. Media Images of Nanotechnology," Paper presented at the conference Imaging and Imagining NanoScience and Engineering, Columbia, SC, 3-7 March.

Stephenson, N. (1995) The Diamond Age, or, Young Lady's Illustrated Primer. New York: Bantam Books.

Wasserman, S. and Faust, K. (1994) Social Network Analysis: Methods and Applications. Cambridge: Cambridge University Press.

\section{Author}

Joachim Schummer is Heisenberg Fellow at the Department of Philosophy, University of Darmstadt, Schloss, 64283 Darmstadt, Germany, and Adjunct Professor at the Department of Philosophy, University of South Carolina, Columbia, SC 29205, USA; e-mail: js@ hyle.org 